\title{
Malaria Transmission and Prospects for Malaria Eradication: The Role of the Environment
}

\author{
Marcia C. Castro \\ Department of Global Health and Population, Harvard T.H. Chan School of Public Health, Boston, \\ Massachusetts 02115 \\ Correspondence: mcastro@hsph.harvard.edu
}

\begin{abstract}
Environmental factors affect the transmission intensity, seasonality, and geographical distribution of malaria, and together with the vector, the human, and the parasite compose the malaria system. Strategies that alter the environment are among the oldest interventions for malaria control, but currently are not the most prominent despite historical evidence of their effectiveness. The importance of environmental factors, the role they play considering the current goals of malaria eradication, the different strategies that can be adopted, and the current challenges for their implementation are discussed. As malaria elimination/eradication takes a prominent place in the health agenda, an integrated action, addressing all elements of the malaria system, which contributes to improved knowledge and to building local capacity and that brings about positive effects to the health of the local population has the greatest chance to produce fast, effective, and sustainable results.
\end{abstract}

"Ike chess, (malaria) is played with a few Lieces, but is capable of an infinite variety of situations" (Hackett 1937). Four pieces comprise the malaria system: the vector, the parasite, the human, and the environment (Table 1). The triad human-vector-parasite exists within (and interacts with) the environment, resulting in a variety of unique local patterns of malaria transmission that have been associated with specific definitions (e.g., forest malaria, urban malaria, frontier malaria). Each of these unique transmission patterns present distinct challenges, requiring a tailored package of control interventions.

A multitude of factors impact each of the four pieces in the malaria system, adding complexity to the proper understanding and control of malaria (Singer and Castro 2011). The vector is shaped by the type of Anopheles species and associated feeding, resting, biting, and breeding behavior, flight range, vectorial capacity, mortality and reproduction rate, mosquito resistance to insecticides, and larval resistance to larvicides. Important issues regarding the parasite include the type and strain, resistance to antimalarial drugs, and duration of infection. The human component is shaped by several factors including genetic and acquired immunity, behavior, demographics, culture, socioeconomic characteristics, and politics. Last, the environment component depends both on the natural environment-temperature, humidity, rainfall, soil quality, elevation/slope, land cover, hydrography, presence of natural enemies of

Editors: Dyann F. Wirth and Pedro L. Alonso

Additional Perspectives on Malaria: Biology in the Era of Eradication available at www.perspectivesinmedicine.org

Copyright (C) 2017 Cold Spring Harbor Laboratory Press; all rights reserved; doi: 10.1101/cshperspect.a025601

Cite this article as Cold Spring Harb Perspect Med 2017;7:a025601 
M.C. Castro

Table 1. A systemic view of malaria: Factors, control strategies, and challenges

\begin{tabular}{|c|c|c|c|}
\hline Elements & Factors & Control strategies & Challenges \\
\hline Vector & $\begin{array}{l}\text { Species; feeding, resting, biting, } \\
\text { host, and breeding } \\
\text { preference; flight range; life } \\
\text { span; vectorial capacity; } \\
\text { reproduction rate; resistance }\end{array}$ & $\begin{array}{l}\text { Insecticide-treated nets; } \\
\text { indoor residual spraying; } \\
\text { larval source management; } \\
\text { fogging or area spraying }\end{array}$ & $\begin{array}{l}\text { Mosquito behavior change; } \\
\text { insecticide resistance; novel } \\
\text { vector control (traps, } \\
\text { engineered mosquitoes); } \\
\text { genetic differences }\end{array}$ \\
\hline Parasite & $\begin{array}{l}\text { Type and strain; resistance to } \\
\text { antimalarials; duration of } \\
\text { infection }\end{array}$ & $\begin{array}{l}\text { Case management; malaria } \\
\text { seasonal chemoprevention; } \\
\text { intermittent presumptive } \\
\text { treatment; mass drug } \\
\text { administration }\end{array}$ & $\begin{array}{l}\text { New diagnostic tools; sub- } \\
\text { microscopic parasitemia; } \\
\text { asymptomatic infections; } \\
\text { gametocyte cycle; genetic } \\
\text { diversity; hypnozoites; } \\
\text { drug resistance; vaccines }\end{array}$ \\
\hline Human & $\begin{array}{l}\text { Genetic/acquired immunity; } \\
\text { knowledge (transmission, } \\
\text { prevention, treatment); age; } \\
\text { migratory pattern; } \\
\text { occupation; education; } \\
\text { cultural beliefs; behavior; } \\
\text { access to care; population } \\
\text { density; political context } \\
\text { (public health interventions, } \\
\text { support and infrastructure, } \\
\text { construction of major } \\
\text { development projects, } \\
\text { implementation of foreign } \\
\text { assistance, political stability, } \\
\text { and governance); } \\
\text { globalization (market } \\
\text { pressures, choice of crops, } \\
\text { exploitation of natural } \\
\text { resources); environmental } \\
\text { change }\end{array}$ & $\begin{array}{l}\text { Personal protection } \\
\text { (repellents, protective } \\
\text { clothing); behavior change } \\
\text { communication }\end{array}$ & $\begin{array}{l}\text { Community participation; } \\
\text { adherence to control; risk } \\
\text { perception; behavior } \\
\text { change; human mobility; } \\
\text { forced mobility (climate, } \\
\text { conflicts); malaria in } \\
\text { pregnancy } \\
\text { Scale-up; sustainability of } \\
\text { recent achievements; } \\
\text { funding (donor fatigue); } \\
\text { political commitment; } \\
\text { intersectoral collaboration; } \\
\text { strong health system; } \\
\text { surveillance; counterfeit } \\
\text { drugs; affordable drugs; } \\
\text { supply chain management }\end{array}$ \\
\hline Environment & $\begin{array}{l}\text { Natural: temperature, rainfall, } \\
\text { humidity; elevation/slope; } \\
\text { soil quality; vegetation; } \\
\text { hydrology; presence of } \\
\text { natural enemies of } \\
\text { mosquitoes and larvae; } \\
\text { natural disasters } \\
\text { Human-made: urbanization; } \\
\text { land change/use; housing } \\
\text { type; deforestation; } \\
\text { infrastructure (water, waste } \\
\text { collection, sanitation); } \\
\text { development projects (dams, } \\
\text { roads, oil pipelines, mining, } \\
\text { railways, irrigation, } \\
\text { resettlement); disasters } \\
\text { facilitated by human change }\end{array}$ & $\begin{array}{l}\text { Environmental management; } \\
\text { house improvement }\end{array}$ & $\begin{array}{l}\text { Infrastructure projects; } \\
\text { environmental change; } \\
\text { extreme climatic events }\end{array}$ \\
\hline
\end{tabular}


mosquitoes and larvae, and natural disastersand the human-made environment-land use, land change, deforestation, housing type, infrastructure (water, sanitation, and waste collection), urbanization, development projects (e.g., roads, railways, dams, irrigation, mining, resettlement projects, and oil pipelines), and disasters facilitated by human-made changes.

Each of these factors may affect malaria positively or negatively, and effects can be modified depending on how they interact with each other. In addition, many of these factors are not static, but rather change/adapt to pressure or novel local conditions, bringing about additional challenges for malaria control. Examples include the development of drug and insecticide resistance, changes in vector (Chinery 1984; Sattler et al. 2005; Awolola et al. 2007) and human behavior (Maheu-Giroux and Castro 2013), and environmental changes (Keiser et al. 2004; Gething et al. 2010; Castro and Singer 2011; Yamana and Eltahir 2013; Hahn et al. 2014). Therefore, although specific interventions target each of the four pieces that compose the malaria system, two equally important issues deserve special attention. First, efforts to control (and eventually eradicate) malaria must address all four components of the malaria system. Second, the implementation of a package of interventions must be accompanied by a surveillance effort that allows fine tuning strategies in the event of changing local conditions.

This article focuses on the environmental component of the malaria system, considering (1) its interactions with other elements in the system, (2) the ways through which control strategies could address environmental determinants, and (3) if and why considering the environmental component is crucial for current goals of malaria eradication.

\section{ENVIRONMENTAL DETERMINANTS OF MALARIA TRANSMISSION}

Several environmental factors impact mosquito and parasite vital rates, and thus affect the transmission intensity, seasonality, and geographical distribution of malaria. These factors fall into two broad categories: natural and human-made environment, as detailed next.

\section{Natural Environment}

Climate-based factors, temperature and precipitation, are the primary environmental determinants of malaria. Temperature impacts vector and parasite development and thus is an important constraint on the geographical suitability to malaria (Gething et al. 2011). The extrinsic development of the parasite is constrained within a certain temperature range (Macdonald 1957), extremely high temperatures are likely to produce smaller and less fecund mosquitoes (Warrell and Gilles 2002), and increasing temperatures reduce the time for mosquito maturation (from larva to adult form) and increase the feeding frequency (Service 1980; Martens et al. 1999). Recent models indicate that malaria transmission (as measured by the $R_{0}$ ) is constrained to temperatures between $16^{\circ} \mathrm{C}$ and $34^{\circ} \mathrm{C}$, with optimal transmission at $25^{\circ} \mathrm{C}$ (Mordecai et al. 2013), $\sim 6^{\circ} \mathrm{C}$ lower than previously estimated (Martens et al. 1997; Craig et al. 1999; Parham and Michael 2010).

The frequency, duration, and intensity of precipitation contribute to the formation of suitable water habitats for mosquito breeding. Although water pools must persist for a long enough time for mosquito development, heavy precipitation has been associated with immature mortality (Paaijmans et al. 2007). Because Anopheles mosquitoes have different breeding preferences, and other natural conditions such as water temperature and quality, soil characteristics, and vegetation cover (Yamana and Eltahir 2013) can modify the suitability of the aquatic habitat for mosquito development, the relationship between rainfall and malaria has produced contrasting results, with some studies reporting positive impacts (Loevinsohn 1994; Kilian et al. 1999; Lindblade et al. 1999), and others finding negative or nonsignificant ones (Lindsay et al. 2000; WHO 2000; Singh and Sharma 2002).

Extreme weather events (e.g., tropical storms, droughts, hurricanes, cyclones, typhoons) often have the most dramatic impacts on human health (Kovats et al. 1999). The El 
M.C. Castro

Niño Southern Oscillation (ENSO) is a phenomenon often associated with extreme weather events across the globe, with significant impacts in malaria transmission (Kovats et al. 2003). Although the periodicity of ENSO varies, early warning systems (some up to 1 year ahead) that monitor sea surface temperature facilitate the adoption of measures in anticipation of the consequences of extreme weather events ( $\mathrm{Lu}-$ descher et al. 2014).

Local hydrography, hydrology, and topography affect the water flow and collection, and the formation of water pools (Bomblies et al. 2008; Yamana and Eltahir 2013). For example, in the Amazon region the water level of the rivers increases dramatically during the rainy season, flooding the areas immediately proximal to the margins. When the rainy season is ending the water level decreases, and pools of water suitable for mosquito breeding appear because of the irregularity of the terrain (Peixoto 1917).

The presence of natural predators of mosquito larvae can contribute to control the population size of malaria vectors, depending on the physicochemical properties of the water habitat (Dida et al. 2015). Humidity affects mosquito survival, because under very dry conditions mosquitoes will desiccate (Jawara et al. 2008). Last, natural disasters can also result in increased malaria transmission (Watson et al. 2007) through population displacement, and habitat change after an earthquake and flooding that facilitate the proliferation of mosquito breeding habitats (Sáenz et al. 1995; Gagnon et al. 2002). In contrast to the ENSO phenomenon, natural disasters often happen without warning, leaving little room to plan in anticipation of their negative impacts.

\section{Human-Made Environment}

Human-made transformations of the natural environment serve many purposes and can result in reductions or increases in malaria transmission. The implementation of development projects, such as roads, railways, dams, irrigation, mining, population resettlement, and oil extraction, to name a few, often result in social and environmental impacts that, if not properly assessed and mitigated, bring about negative effects on people's health. Such impacts are associated with, for example, deforestation that can create ideal breeding grounds for mosquitoes; migration of naive populations to malariaendemic areas, or migration of infected people to areas where the malaria vector is present and transmission, albeit absent or very low, is suitable; a large concentration of workers living in poor housing and thus highly exposed to the vector; and creation of ideal water habitats for mosquito breeding, such as artificial lakes associated with dam construction. These and other consequences of development projects, as well as the negative impacts on health, have been well documented for more than a century (e.g., Cruz 1972; Ghebreyesus et al. 1999; Lerer and Scudder 1999; Jackson and Sleigh 2000; Keiser et al. 2005a; Knoblauch et al. 2014). Nevertheless, they continue to happen and to threaten the lives of many in malaria-endemic areas, exposing major flaws in the transparency and execution of environmental impact assessments (Erlanger et al. 2008).

The massive deforestation observed in the Brazilian Amazon in the 1970s and 1980s (driven by large cattle-ranching and human settlement efforts) was associated with a major increase of malaria, and brought about a new definition to describe the dynamics of transmission in the region: frontier malaria (Sawyer and Sawyer 1987; Castro et al. 2006). It has been hypothesized that extensive deforestation and disorganized occupation could be indirectly responsible for modifications in mosquito behavior (outdoor biting), subtracting its former sources of food (wild animals, who were scared away by the new settlers) and bringing man closer to its breeding places (Deane 1988).

Regarding agriculture, the impact on malaria depends on the type of crop, the planting system, the irrigation practice, and the characteristics of the local Anopheles (Yasuoka and Levins 2007). Without proper management of irrigation, rice fields often provide ideal grounds for mosquito breeding (International Rice Research Institute and Joint WHO/FAO/UNEP Panel of Experts on Environmental Management for Vector Control 1988). Specifically related to 
maize, it has been shown that its pollen is a nutritious food for the larvae of the most common malaria vector in Ethiopia, contributing to increasing vector density, mosquito longevity, and malaria infection (Ye-Ebiyo et al. 2000; Kebede et al. 2005). Also, the practice of cultivating crops such as sweet potato and beans, among others, using raised planting beds interspaced by channels that naturally provide irrigation result in highly productive breeding habitats for Anopheles (Dongus et al. 2009).

The availability of basic infrastructure (water, sanitation, waste collection) in residential areas is another factor that can modify human exposure to a malaria infection, depending on the characteristics of local malaria vectors. The need to collect water from streams or closer to areas where mosquito density is higher, to bathe in rivers, and to defecate and urinate near forested areas around villages are associated with a higher human-vector contact (Castro et al. 2006; Gryseels et al. 2015). Also, the accumulation of waste that can block the water flow of drains contribute to the formation of water pools ideal for mosquito breeding (Castro et al. 2010).

The process of urbanization is expected to contribute to lower malaria transmission through better health care, improved house construction, and a reduced number of breeding habitats for Anopheles mosquitoes caused by water pollution and large areas of impervious surface (Castro et al. 2004; De Silva and Marshall 2012). However, declining economies, uncontrolled urban growth (with large fractions of the population living under slum-like conditions lacking proper infrastructure), and adaptation of malaria vectors to the urban environment bring additional challenges to urban malaria control (Chinery 1984; Keiser et al. 2004).

Another important aspect of the humanmade environment is the housing quality and the extent to which it offers a barrier against the malaria vector. In malaria-endemic areas, houses with open eaves, without screens, and without doors and/or windows offer higher risk of human-vector contact and are associated with higher malaria transmission (Sawyer and Sawyer 1987; Gamage-Mendis et al. 1991; Tusting et al. 2015).

\section{ENVIRONMENT-BASED INTERVENTIONS FOR MALARIA CONTROL}

Strategies that alter the environmental characteristics associated with malaria transmission are among the oldest interventions for malaria control (Stromquist 1920). They can be grouped into three types of activities, aiming to reduce the number of breeding habitats for malaria vectors or to reduce the human-vector contact. First, a permanent modification of the environment, such as drainage, filling, and land leveling; these activities often demand largescale engineering work. Second, a manipulation of the environment that demands recurrent activities, such as regulation of water level in reservoirs, intermittent irrigation, afforestation/ deforestation, and vegetation removal from water bodies. Third, modification of human habitation through resettlement or improved housing (WHO 1982).

Environmental management was crucial for the elimination of malaria in European countries and in the United States and to reduce the burden of the disease in many other locations (Pomeroy 1920; Boyd 1926; Neiva 1940). Important endeavors, including the construction of the Panama Canal (Gorgas 1915), copper mining in Zambia, former Rhodesia (Watson 1953; Utzinger et al. 2002), and rubber production in Malaysia (Watson 1921), were unlikely to have the same outcome if environmental management was not adopted as part of the package of interventions for malaria control. Malaria transmitted by a bromeliad-breeding mosquito was eliminated from the South of Brazil through removal of bromeliads from urban areas and introduction of eucalyptus trees (on which bromeliads do not grow) in forested areas (Pinotti 1951; Deane 1988). Housing improvement, first introduced by the Italian hygienist Angelo Celli at the end of the 19th century, was a crucial intervention in Europe, in the United States, and during wars (screening barracks) (Carter and Mendis 2002; Lindsay et al. 2002). The use of intermittent irrigation 
M.C. Castro

strategies for control of rice-field malaria has been and continues to be an important strategy in China (Baolin 1988; Singer and Castro 2011).

The historical examples of the successful use of environmental management are many, both in urban and rural settings, and they proved to be cost effective (Konradsen et al. 2004; Keiser et al. 2005b). A few lessons learned include the combination of control strategies (with environment management playing a central role) idiosyncratic to each locality, the multidisciplinary nature of the control staff (entomologist, epidemiologist, ecologist, hydrologist, physician, and engineer), the importance of surveillance to inform the need to fine-tune the package of interventions, and the recognition that about 3 years would be necessary to obtain expected results (B Singer, unpubl.).

Lessons from contemporary environmental management for malaria control are twofold. First, it should be established with the participation of the community, which contributes to the sustainability of the activity and promotes a sense of ownership and empowerment (Fillinger et al. 2008; Castro et al. 2009). Second, multisectoral collaboration should be pursued, integrating health actions with sectors responsible for agriculture, urban planning, transportation, education, and finance (United Nations Development Programme and Roll Back Malaria Partnership 2013).

Currently, environmental management has very low priority, maybe as a result of the urgent desire for novel technologies that could quickly resolve the malaria problem (Lindsay et al. 2002). The opportunity, however, not only exists but is unique at a time when malaria eradication is back to the health agenda, as detailed in the next section.

\section{FUTURE PERSPECTIVES}

Inspired by the 2007 Gates Malaria Forum, malaria eradication came back to the global health agenda. Malaria-endemic countries intensified control measures, particularly indoor residual spraying, use of artemisinin combination therapy for treatment, and distribution of insecticide treated nets. Significant progress has been achieved, and since the year 2000, the average prevalence of malaria infection in children aged $2-10$ has declined by $47 \%$, and an increasing number of countries are moving toward malaria elimination. Despite these achievements, there are still 198 million cases of malaria, about 584,000 deaths annually (WHO 2014), and challenges abound (Table 1).

Specifically related to the environment, existing unfavorable conditions as well as ongoing and projected environmental changes must be analyzed considering the interactions between the different elements in the malaria system. For example, environmental transformations may result in vector behavior change, imposing constraints on vector control interventions (Ferguson et al. 2010). This complexity of the system deserves more careful attention by malaria control programs, as exemplified next.

Housing improvements that could help reduce malaria transmission include screening of doors, windows, and eaves, closing eaves, installing ceilings, improving roofs, sealing cracks in walls, using higher quality building materials, creating new housing designs, and installing eave tubes (Lindsay et al. 2002; Ogoma et al. 2009; Tusting et al. 2015). Those are applicable in areas where conditions leave inhabitants highly exposed to contact with malaria vectors, such as urban and rural areas where poor housing prevails, and in refugee camps. The increase in conflicts that force populations into refugee camps (Rowland and Nosten 2001) and the increase in the frequency and intensity of natural disasters (IPCC 2013), demanding quick housing solutions, are two examples of current and future threats to malaria eradication efforts that could be mitigated with housing improvement, combined with other interventions.

In addition, current patterns of urban growth that result in concentration of poor housing and lack of infrastructure can facilitate the vector adaptation to water habitats that traditionally would not be suitable for mosquito breeding, and the creation of pockets of malaria infection among worse off areas. In this regard, recent population trends show that although currently Africa is the least urbanized region ( $40 \%$ of the population living in urban areas), 
it shows the fastest pace of urbanization and by 2050, 56\% of its population will be living in urban areas (United Nations et al. 2015). Thus, in anticipation of major changes, intersectoral collaboration becomes crucial. Environmental management strategies should be implemented concurrently with city growth, minimizing the negative effects commonly associated with rapid and unplanned urbanization (United Nations et al. 2015).

Also, environmental management is likely to increase the return of other malaria control interventions. For example, in Dar es Salaam, a third of all anopheline-positive water habitats were found in drains (Castro et al. 2010). Considering that the city has included larval control in the package of interventions, the cost and effort invested in that activity could be reduced if drains were regularly maintained to prevent water stagnation. The initial cost of cleaning drains may be high, given the massive accumulation of waste materials after years of lacking proper maintenance. However, in the long run, costs of keeping drains clean are lower than the resources needed to acquire and apply larvicides in the drains (UMCP et al. 2007; Castro et al. 2009). In addition, the use of environmental management strategies is likely to impact other vector-borne diseases (e.g., dengue and lymphatic filariasis), contributing to a much broader health improvement.

Although expanding areas protected under environmental conservation policies would be beneficial to prevent an increase in malaria transmission (Bauch et al. 2015), current trends make it reasonable to expect that deforestation will continue to be a reason for concern, particularly in the Amazon forest, driven by cattle ranching, agriculture, mining, large-scale development projects, and land invasions. When deforestation is planned and/or anticipated because of a specific activity that is implemented through legally approved mechanisms (e.g., development projects), there is an opportunity to adopt mitigation strategies to prevent increases in vector density and in malaria transmission. To be successful, however, these strategies must be closely monitored. In contrast, when deforestation results from illegal operations there is no planning, no warning, and thus no opportunity to counteract the impacts on malaria. In such a scenario, outbreaks are often observed, and responses only happen after a major health problem has already happened.

Considered as the biggest global health threat of the 21st century (Costello et al. 2009; WHO 2009; Watts et al. 2015), climate change is a significant environmental change currently unfolding, with worldwide consequences. Climatic effects on vector-borne diseases can occur directly, through extreme events (e.g., drought, flooding), increases in average temperature, and changes in precipitation patterns, but also indirectly, by population displacement and water and food insecurity, which impact individuals' exposure and vulnerability to infections.

Despite the uncertainty embedded in climate change scenarios (IPCC 2013), malaria burden is likely to be impacted by climate change. The magnitude of the impact will depend on many issues, such as (1) the pattern of variability in temperature (Paaijmans et al. 2010); (2) how countries are planning in anticipation of future changes; (3) how adaptation strategies are adopted at varied scales (individual, community, institutional); (4) the combination of malaria control strategies in place; (5) the extent to which the risk of infection determined by local characteristics can be augmented by climatic changes; and (6) the level of clinical immunity (Laneri et al. 2015). Such complexity is reflected by contrasting results of global models on the impact of climate change on malaria (Martens et al. 1999; Rogers and Randolph 2000; Pascual et al. 2006; Gething et al. 2010; Yamana and Eltahir 2013; Laneri et al. 2015). The impacts and the responses are unlikely to be uniform across and within regions (Takken et al. 2005), and this adds another layer of complexity to the efforts of malaria eradication.

\section{CONCLUDING REMARKS}

Environmental factors affect malaria transmission in different ways depending on the local ecosystem and on the transformations it has suffered through human action. They also interact with other elements of the malaria system, 
M.C. Castro

resulting in a variety of local transmission profiles. This is a characteristic of malaria that adds complexity to disease control and elimination. There is no unique combination of control strategies that works in every setting, and each must be tailored to address local characteristics of transmission.

As malaria-endemic countries embrace elimination goals, focus has been given to testing, treatment, and vector control by indoor residual spraying and insecticide treated nets. Overall, environmental aspects have not received much attention by malaria control programs. One could argue that potential reasons include (1) limited financial and human resources; (2) lack of local expertise integrating health, hydrology, and engineering; (3) restricted knowledge on the additional benefit of adopting environmental management in different settings in combination with other interventions already in place; and (4) the desire to find a new technological solution.

It is unquestionable that progress in reducing cases and deaths has been achieved in the past decade, although not uniformly across and within countries. Although significant reductions can be achieved without control strategies that focus on the environment, the assumption that a fully successful control program can exist while neglecting environmental issues is naïve, and a mistake from a programmatic point of view.

Arguments favoring environmental interventions are threefold. First, by targeting all elements of the malaria system progress toward elimination can be faster and more cost effective. Because the elements of the system interact with each other, the returns from interventions can be maximized by concurrently addressing all elements, for example, human behavior affects the impact of other interventions (such as bednet use). Thus, by including behavior change campaigns in the control package it is possible to maximize local acceptance and updates of other interventions; also, environmental management can contribute to reducing the costs of other interventions, such as use of larviciding. Second, gains are likely to be sustainable. Because environmental strategies target the source of the problem (from a vector point of view) and have a long-term impact (if properly maintained), it is expected that the direct benefits, and interactions with other elements in the malaria system, will last longer. Third, environmental management benefits go beyond malaria and are expected to also affect the incidence of dengue, lymphatic filariasis, and other vector-borne diseases. Thus, by promoting a healthier environment, these interventions make an important contribution to the overall improvement of local health conditions, probably reaching out to populations that are not directly benefited by other malaria control interventions.

Environmental management strategies have been successfully implemented in malaria-endemic settings in the past (Keiser et al. 2005b). The knowledge regarding what/how to do is available, and so is the evidence regarding its impact. Considering the current scenario, where (1) changes to the environment are fast, often unplanned, significantly favoring vector breeding, and thus should be mitigated, (2) extreme weather events are more frequent and intense, and therefore adaptation strategies are urgently needed, and (3) vectors adapt to urban ecologies, breeding in places previously considered to be unsuitable for larval development, failing to introduce environmental strategies into the package of malaria control interventions is a missed opportunity with implications for the success and sustainability of other control efforts. However, the adoption of environmental strategies demands local knowledge and expertise: knowledge to identify places where targeting the environment is feasible and beneficial to the reduction of malaria transmission; entomological knowledge on vector species composition and behavior; and expertise to plan, implement, maintain, and monitor the activities.

Realistically, it is probably the case that most malaria control programs do not have the proper knowledge and expertise to effectively account for the local environment in control efforts, and maybe do not even have comprehensive entomological information (Ulrich et al. 2013). Thus, filling in these gaps is imperative, and the task could be better accomplished 
by fostering an integrated collaboration between donors, the industry, academia, and different sectors of the government (United $\mathrm{Na}$ tions Development Programme and Roll Back Malaria Partnership 2013).

One of the challenges for incorporating environmental interventions is funding. Most resources are placed on interventions that have shown to be effective in bringing about significant declines in transmission in high-endemic countries (bednets, indoor residual spraying, and treatment). However, if a plateau is achieved, and those interventions are not able to promote further declines, what is the next step? Incorporation of other well-known but currently less used interventions, such as environmental management, may lack the political and financial support because funding agencies might not be willing to sponsor them on the grounds that (1) they are not novel, (2) they are not a priority, or (3) the country has no knowledge and expertise to implement them. Depending on the local characteristics of malaria transmission, such a scenario may hamper attempts to quickly move toward elimination.

As elimination/eradication takes a prominent place in the health agenda of malaria-endemic countries; an integrated action, addressing all elements of the malaria system, which contributes to improve knowledge and to build local capacity, and that brings about positive effects to the health of the local population, has the greatest changes to produce fast, effective, and sustainable results.

\section{REFERENCES}

Awolola TS, Oduola AO, Obansa JB, Chukwurar NJ, Unyimadu JP. 2007. Anopheles gambiae s.s. breeding in polluted water bodies in urban Lagos, southwestern Nigeria. J Vector Borne Dis 44: 241-244.

Baolin L. 1988. Environmental management for the control of ricefield-breeding mosquitoes in China. Vector-borne disease control in humans through rice agroecosystem management. Proceedings of the Workshop on Research and Training Needs in the Field of Integrated Vector-Borne Disease Control in Riceland Agroecosystems of Developing Countries. March 9-14, 1987 (ed. IRR Institute), pp. 111-121. International Rice Research Institute in collaboration with the WHO/FAO/UNEP Panel of Experts on Environmental Management for Vector Control, Manila, Philippines.
Bauch SC, Birkenbach AM, Pattanayak SK, Sills EO. 2015. Public health impacts of ecosystem change in the Brazilian Amazon. Proc Natl Acad Sci 112: 7414-7419.

Bomblies A, Duchemin JB, Eltahir EAB. 2008. Hydrology of malaria: Model development and application to a Sahelian village. Water Resources Res 44: W12445.

Boyd MF. 1926. The influence of obstacles unconsciously erected against anophelines (housing and screening) upon the incidence of malaria. Am J Trop Med Hyg 6: $157-160$.

Carter R, Mendis KN. 2002. Evolutionary and historical aspects of the burden of malaria. Clin Microbiol Rev 15: 564-594.

Castro MC, Singer BH. 2011. Malaria in the Brazilian Amazon. In Water and sanitation related diseases and the environment: Challenges, interventions and preventive measures (ed. Selendy J), pp. 401-420. Wiley, Hoboken, NJ.

Castro MC, Yamagata Y, Mtasiwa D, Tanner M, Utzinger J, Keiser J, Singer BH. 2004. Integrated urban malaria control: A case study in Dar es Salaam, Tanzania. Am J Trop Med Hyg 71: 103-117.

Castro MC, Monte-Mór RL, Sawyer DO, Singer BH. 2006. Malaria risk on the Amazon frontier. Proc Natl Acad Sci 103: $2452-2457$.

Castro MC, Tsuruta A, Kanamori S, Kannady K, Mkude S. 2009. Community-based environmental management for malaria control: Evidence from a small-scale intervention in Dar es Salaam, Tanzania. Malaria J 8: 57.

Castro MC, Kanamori S, Kannady K, Mkude S, Killeen GF, Fillinger U. 2010. The importance of drains for the larval development of lymphatic filariasis and malaria vectors in Dar es Salaam, United Republic of Tanzania. PLoS Negl Trop Dis 4: e693.

Chinery WA. 1984. Effects of ecological changes on the malaria vectors Anopheles funestus and the Anopheles gambiae complex of mosquitoes in Accra, Ghana. J Trop Med Hyg 87: 75-81.

Costello A, Abbas M, Allen A, Ball S, Bell S, Bellamy R, Friel S, Groce N, Johnson A, Kett M, et al. 2009. Managing the health effects of climate change. Lancet 373: 1693-1733.

Craig MH, Snow RW, le Sueur D. 1999. A climate-based distribution model of malaria transmission in subSaharan Africa. Parasitol Today 15: 105-111.

Cruz OG. 1972. Madeira-Mamoré Railway Company: Considerações gerais sobre as condições sanitárias do rio Madeira. 1910 [Madeira Mamoré Railway Company: Overall assessment of the sanitary conditions of the Madeira River. 1910]. In Opera ominia (ed. Cruz OG), pp. 564-624. Instituto Oswaldo Cruz, Rio de Janeiro.

Deane LM. 1988. Malaria studies and control in Brazil. Am J Trop Med Hyg 38: 223-230.

De Silva PM, Marshall JM. 2012. Factors contributing to urban malaria transmission in sub-Saharan Africa: A systematic review. J Trop Med 2012: 819563.

Dida G, Gelder F, Anyona D, Abuom P, Onyuka J, Matano AS, Adoka S, Kanangire C, Owuor P, Ouma C, et al. 2015. Presence and distribution of mosquito larvae predators and factors influencing their abundance along the Mara River, Kenya and Tanzania. SpringerPlus 4: 136. 
M.C. Castro

Dongus S, Nyika D, Kannady K, Mtasiwa D, Mshinda H, Gosoniu L, Drescher AW, Fillinger U, Tanner M, Killeen GF, et al. 2009. Urban agriculture and Anopheles habitats in Dar es Salaam, Tanzania. Geospatial Health 3: 189-210.

Erlanger TE, Krieger GR, Singer BH, Utzinger J. 2008. The 6/94 gap in health impact assessment. Environ Impact Assess Rev 28: 349-358.

Ferguson HM, Dornhaus A, Beeche A, Borgemeister C, Gottlieb M, Mulla MS, Gimnig JE, Fish D, Killeen GF 2010. Ecology: A prerequisite for malaria elimination and eradication. PLoS Med 7: e1000303.

Fillinger U, Kannady K, William G, Vanek MJ, Dongus S, Nyika D, Geissbuhler Y, Chaki P, Govella NJ, Mathenge E, et al. 2008. A tool box for operational mosquito larval control: Preliminary results and early lessons from the urban malaria control programme in Dar es Salaam, Tanzania. Malaria J 7: 20.

Gagnon AS, Smoyer-Tomic KE, Bush ABG. 2002. The El Niño southern oscillation and malaria epidemics in South America. Int J Biometeorol 46: 81-89.

Gamage-Mendis AC, Carter R, Mendis C, De Zoysa AP, Herath PR, Mendis KN. 1991. Clustering of malaria infections within an endemic population: Risk of malaria associated with the type of housing construction. Am J Trop Med Hyg 45: 77-85.

Gething PW, Smith DL, Patil AP, Tatem AJ, Snow RW, Hay SI. 2010. Climate change and the global malaria recession. Nature 465: 342-346.

Gething P, Van Boeckel T, Smith D, Guerra C, Patil A, Snow R, Hay S. 2011. Modelling the global constraints of temperature on transmission of Plasmodium falciparum and P. vivax. Parasit Vectors 4: 92.

Ghebreyesus TA, Haile M, Witten KH, Getachew A, Yohannes AM, Yohannes M, Teklehaimanot HD, Lindsay SW, Byass P. 1999. Incidence of malaria among children living near dams in northern Ethiopia: Community based incidence survey. BMJ 319: 663-666.

Gorgas GWC. 1915. Sanitation in Panama. Appleton, New York.

Gryseels C, Durnez L, Gerrets R, Uk S, Suon S, Set S, Phoeuk P, Sluydts V, Heng S, Sochantha T, et al. 2015. Re-imagining malaria: Heterogeneity of human and mosquito behaviour in relation to residual malaria transmission in Cambodia. Malaria J 14: 165.

Hackett L. 1937. Malaria in Europe: An ecological study. Oxford University Press, London.

Hahn MB, Gangnon RE, Barcellos C, Asner GP, Patz JA. 2014. Influence of deforestation, logging, and fire on malaria in the Brazilian Amazon. PLOS ONE 9: e85725.

International Rice Research Institute, Joint WHO/FAO/ UNEP Panel of Experts on Environmental Management for Vector Control. 1988. Vector-borne disease control in humans through rice agroecosystem management. Proceedings of the Workshop on Research and Training Needs in the Field of Integrated Vector-Borne Disease Control in Riceland Agroecosystems of Developing Countries. March 914, 1987. International Rice Research Institute in collaboration with the WHO/FAO/UNEP Panel of Experts on Environmental Management for Vector Control, Manila, Philippines.

IPCC. 2013. Final draft underlying scientific-technical assessment. IPCC 5th assessment report "Climate change 2013:
The physical science basis," Working Group I-12th Session. Stockholm, September 23-26, 2013, www.ipcc.ch/ report/ar5/wg1/\#.UkveNn_gFTU.

Jackson S, Sleigh A. 2000. Resettlement for China's Three Gorges Dam: Socio-economic impact and institutional tensions. Communis Post-Commun 33: 223-241.

Jawara M, Pinder M, Drakeley CJ, Nwakanma DC, Jallow E, Bogth C, Lindsay SW, Conway DJ. 2008. Dry season ecology of Anopheles gambiae complex mosquitoes in The Gambia. Malaria J 7: 156.

Kebede A, McCann JC, Kiszewski AE, Ye-Ebiyo Y. 2005. New evidence of the effects of agro-ecologic change on malaria transmission. Am J Trop Med Hyg 73: 676-680.

Keiser J, Utzinger J, Castro MC, Smith T, Tanner M, Singer BH. 2004. Urbanization in sub-Saharan Africa and implications for malaria control. Am J Trop Med Hyg 71: $118-127$.

Keiser J, Castro MC, Maltese MF, Bos R, Tanner M, Singer BH, Utzinger J. 2005a. Effect of irrigation and large dams on the burden of malaria on global and regional scale. Am J Trop Med Hyg 72: 392-406.

Keiser J, Singer BH, Utzinger J. 2005b. Reducing the burden of malaria in different eco-epidemiological settings with environmental management: A systematic review. Lancet Infect Dis 5: 695-708.

Kilian AH, Langi P, Talisuna A, Kabagambe G. 1999. Rainfall pattern, El Niño and malaria in Uganda. Trans $R$ Soc Trop Med Hyg 93: 22-23.

Knoblauch A, Winkler M, Archer C, Divall M, Owuor M, Yapo R, Yao P, Utzinger J. 2014. The epidemiology of malaria and anaemia in the Bonikro mining area, central Cote d'Ivoire. Malaria J 13: 194.

Konradsen F, van der Hoek W, Amerasinghe FP, Mutero C, Boelee E. 2004. Engineering and malaria control: Learning from the past 100 years. Acta Tropica 89: 99-108

Kovats RS, Bouma MJ, Haines A. 1999. El Niño and health. World Health Organization, Geneva.

Kovats RS, Bouma MJ, Hajat S, Worrall E, Haines A. 2003. El Niño and health. Lancet 362: 1481-1489.

Laneri K, Paul RE, Tall A, Faye J, Diene-Sarr F, Sokhna C, Trape JF, Rodó X. 2015. Dynamical malaria models reveal how immunity buffers effect of climate variability. Proc Natl Acad Sci 112: 8786-8791.

Lerer LB, Scudder T. 1999. Health impacts of large dams. Environ Impact Assess Rev 19: 113-123.

Lindblade KA, Walker ED, Onapa AW, Katungu J, Wilson ML. 1999. Highland malaria in Uganda: Prospective analysis of an epidemic associated with El Niño. Trans R Soc Trop Med Hyg 480-487: 480-487.

Lindsay SW, Bodker R, Malima R, Msangeni HA, Kisinza W. 2000. Effect of 1997-98 El Niño on highland malaria in Tanzania. Lancet 355: 989-990.

Lindsay SW, Emerson PM, Charlwood JD. 2002. Reducing malaria by mosquito-proofing houses. Trends Parasitol 18: $510-514$.

Loevinsohn ME. 1994. Climatic warming and increased malaria incidence in Rwanda. Lancet 343: 714-718.

Ludescher J, Gozolchiani A, Bogachev MI, Bunde A, Havlin S, Schellnhuber HJ. 2014. Very early warning of next El Niño. Proc Natl Acad Sci 111: 2064-2066. 
Macdonald G. 1957. The epidemiology and control of malaria. Oxford University Press, London.

Maheu-Giroux M, Castro MC. 2013. Do malaria vector control measures impact disease-related behaviour and knowledge? Evidence from a large-scale larviciding intervention in Tanzania. Malaria J 12: 422.

Martens WM, Jetten T, Focks D. 1997. Sensitivity of malaria, schistosomiasis and dengue to global warming. Climatic Change 35: 145-156.

Martens P, Kovats RS, Nijhof S, Vries Pd, Livermore MTJ, Bradley DJ, Cox J, McMichael AJ. 1999. Climate change and future populations at risk of malaria. Global Environ Change 9: S89-S107.

Mordecai EA, Paaijmans KP, Johnson LR, Balzer C, BenHorin T, Moor E, McNally A, Pawar S, Ryan SJ, Smith TC, et al. 2013. Optimal temperature for malaria transmission is dramatically lower than previously predicted. Ecol Lett 16: 22-30.

Neiva A. 1940. Profilaxia da malária e trabalhos de engenharia: Notas, comentários, recordações. Revista Clube Engenharia VI: $60-75$.

Ogoma S, Kannady K, Sikulu M, Chaki P, Govella N, Mukabana W, Killeen G. 2009. Window screening, ceilings and closed eaves as sustainable ways to control malaria in Dar es Salaam, Tanzania. Malaria J 8: 221.

Paaijmans KP, Wandago MO, Githeko AK, Takken W. 2007. Unexpected high losses of Anopheles gambiae larvae due to rainfall. PLOS ONE 2: e1146.

Paaijmans KP, Blanford S, Bell AS, Blanford JI, Read AF, Thomas MB. 2010. Influence of climate on malaria transmission depends on daily temperature variation. Proc Natl Acad Sci 107: 15135-15139.

Parham PE, Michael E. 2010. Modeling the effects of weather and climate change on malaria transmission. Environ Health Perspect 118: 620-626.

Pascual M, Ahumada JA, Chaves LF, Rodó X, Bouma M. 2006. Malaria resurgence in the East African highlands: Temperature trends revisited. Proc Natl Acad Sci 103: 5829-5834.

Peixoto A. 1917. O problema sanitário da Amazônia, p. 28. Officinas Graphicas da Bibliotheca Nacional, Rio de Janeiro, Brazil.

Pinotti M. 1951. The biological basis for the campaign against the malaria vectors in Brazil. Trans $R$ Soc Trop Med Hyg 44: 663-682.

Pomeroy AWJ. 1920. The prophylaxis of malaria in Dar es Salaam, East Africa. J Royal Army Med Corps 35: 44-63.

Rogers DJ, Randolph SE. 2000. The global spread of malaria in a future, warmer world. Science 289: 1763-1766.

Rowland M, Nosten F. 2001. Malaria epidemiology and control in refugee camps and complex emergencies. Ann Trop Med Parasitol 95: 741-754.

Sáenz R, Bissell RA, Paniagua F. 1995. Post-disaster malaria in Costa Rica. Prehosp Disaster Med 10: 154-160.

Sattler MA, Mtasiwa D, Kiama M, Premji Z, Tanner M, Killeen GF, Lengeler C. 2005. Habitat characterization and spatial distribution of Anopheles sp. mosquito larvae in Dar es Salaam (Tanzania) during an extended dry period. Malaria J 4: 4.
Sawyer DR, Sawyer DO. 1987. Malaria on the Amazon frontier: Economic and social aspects of transmission and control. CEDEPLAR, Belo Horizonte, Brazil.

Service MW. 1980. A guide to medical entomology. Macmillan, London.

Singer BH, Castro MC. 2011. Reassessing multiple-intervention malaria control programs of the past: Lessons for the design of contemporary interventions. In Water and sanitation related diseases and the environment: Challenges, interventions and preventive measures (ed. Selendy J), pp. 151-166. Wiley, Hoboken, NJ.

Singh N, Sharma VP. 2002. Patterns of rainfall and malaria in Madhya Pradesh, central India. Ann Trop Med Parasitol 96: 349-359.

Stromquist WG. 1920. Malaria control from the engineering point of view. Am J Public Health 10: 497-501.

Takken W, Vilarinhos PTR, Schneider P, Santos F. 2005. Effects of environmental change on malaria in the Amazon region of Brazil. In Environmental change and malaria risk: Global and local implications (ed. Takken W, Martens P, Bogers R), pp. 113-123. Wageningen University, The Netherlands.

Tusting L, Ippolito M, Willey B, Kleinschmidt I, Dorsey G, Gosling R, Lindsay S. 2015. The evidence for improving housing to reduce malaria: A systematic review and metaanalysis. Malaria J 14: 209.

Ulrich JN, Naranjo DP, Alimi TO, Müller GC, Beier JC. 2013. How much vector control is needed to achieve malaria elimination? Trends Parasitol 29: 104-109.

UMCP, IMCP, NMCP, JICA, HSPH. 2007. Assessment of the impact of environmental management on larval presence and prevalence of malaria infection in Dar es Salaam, Tanzania. Survey description and standard operational procedures. Urban Malaria Control Programme (UMCP), Integrated Malaria Control Project (IMCP), Tanzania National Malaria Control Programme (NMCP), Japan International Cooperation Agency (JICA), Harvard School of Public Health (HSPH), Dar es Salaam, Tanzania.

United Nations, Department of Economic and Social Affairs, Population Division. 2015. World urbanization prospects: The 2014 revision, ST/ESA/SER.A/366. United Nations, New York.

United Nations Development Programme, Roll Back Malaria Partnership. 2013. Multisectoral action framework for malaria. United Nations Development Programme (UNDP) and Roll Back Malaria Partnership (RBM), Geneva.

Utzinger J, Tozan Y, Doumani F, Singer BH. 2002. The economic payoffs of integrated malaria control in the Zambian copperbelt between 1930 and 1950. Trop Med Int Health 7: 657-677.

Warrell DA, Gilles HM. 2002. Essential malariology. Arnold, New York.

Watson JT, Gayer M, Connolly MA. 2007. Epidemics after natural disasters. Emerg Infect Dis 13: 1-5.

Watson M. 1921. The prevention of malaria in the Federated Malay States: A record of twenty years' progress. J. Murray, London. 
M.C. Castro

Watson M. 1953. African highway: The battle for health in Central Africa. J. Murray, London.

Watts N, Adger WN, Agnolucci P, Blackstock J, Byass P, Cai W, Chaytor S, Colbourn T, Collins M, Cooper A, et al. 2015. Health and climate change: policy responses to protect public health. Lancet 386: 18611914.

WHO. 1982. Manual on environmental management for mosquito control: With special emphasis on malaria vectors. World Health Organization, Geneva.

WHO. 2000. El Niño and its health impact. World Health Organization (WHO Fact Sheet No. 192 rev.), Geneva.

WHO. 2009. Protecting health from climate change: Global research priorities. World Health Organization, Geneva.
WHO. 2014. World malaria report 2014. World Health Organization, Geneva.

Yamana TK, Eltahir EAB. 2013. Projected impacts of climate change on environmental suitability for malaria transmission in West Africa. Environ Health Perspect 121 1179-1186.

Yasuoka J, Levins R. 2007. Impact of deforestation and agricultural development on anopheline ecology and malaria epidemiology. Am J Trop Med Hyg 76: 450460.

Ye-Ebiyo Y, Pollack RJ, Spielman A. 2000. Enhanced development in nature of larval Anopheles arabiensis mosquitoes feeding on maize pollen. Am J Trop Med Hyg 63: 90-93. 


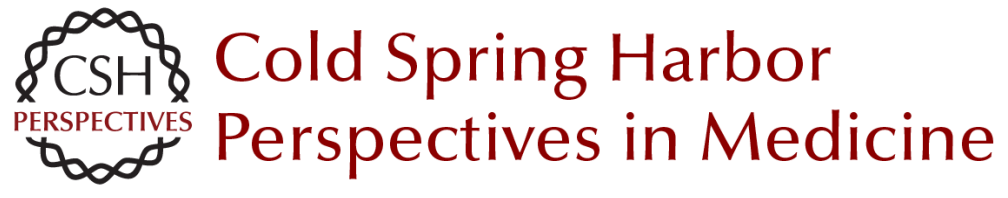

\title{
Malaria Transmission and Prospects for Malaria Eradication: The Role of the Environment
}

\author{
Marcia C. Castro
}

Cold Spring Harb Perspect Med 2017; doi: 10.1101/cshperspect.a025601 originally published online May 10, 2017

\section{Subject Collection Malaria: Biology in the Era of Eradication}

Modern Vector Control

Neil F. Lobo, Nicole L. Achee, John Greico, et al.

Anopheline Reproductive Biology: Impacts on Vectorial Capacity and Potential Avenues for Malaria Control

Sara N. Mitchell and Flaminia Catteruccia

Current and Future Prospects for Preventing

Malaria Transmission via the Use of Insecticides Hilary Ranson

Molecular Signaling Involved in Entry and Exit of Malaria Parasites from Host Erythrocytes Shailja Singh and Chetan E. Chitnis

Vaccines to Accelerate Malaria Elimination and Eventual Eradication

Julie Healer, Alan F. Cowman, David C. Kaslow, et al.

Immune Responses in Malaria Carole A. Long and Fidel Zavala

Antimalarial Drug Resistance: A Threat to Malaria Elimination

Didier Menard and Arjen Dondorp

Malaria during Pregnancy Michal Fried and Patrick E. Duffy
Malaria Pathogenesis

Danny A. Milner, Jr.

Determinants of Malaria Transmission at the

Population Level

Teun Bousema and Chris Drakeley

Host Cell Tropism and Adaptation of Blood-Stage

Malaria Parasites: Challenges for Malaria

Elimination

Caeul Lim, Selasi Dankwa, Aditya S. Paul, et al.

Malaria Transmission and Prospects for Malaria

Eradication: The Role of the Environment Marcia C. Castro

The Biology of Plasmodium vivax John H. Adams and Ivo Mueller

Malaria Genomics in the Era of Eradication Daniel E. Neafsey and Sarah K. Volkman

Malaria Epigenetics Alfred Cortés and Kirk W. Deitsch

Malaria Parasite Liver Infection and Exoerythrocytic Biology Ashley M. Vaughan and Stefan H.I. Kappe

For additional articles in this collection, see http://perspectivesinmedicine.cshlp.org/cgi/collection/ 